\title{
EL PRINCIPIO EMPÍRICO DE IMPOSIBILIDAD Y LA SATISFACCIÓN DE LAS NECESIDADES EN FRANZ HINKELAMMERT
}

\author{
José Manuel Arellano Lázaro*
}

\author{
El hambre es el primero de los conocimientos. \\ Tener hambre es lo primero que se aprende \\ y la ferocidad de nuestras entrañas se enciende, \\ allá donde el estómago se inicia. \\ Miguel Hernández
}

\begin{abstract}
RESUMEN: Para Hinkelammert la acción humana está limitada por varios ámbitos, el económico, el político, el tecnológico, etc., pero en última instancia está limitada por la satisfacción de las necesidades. Ya que aun si el ser humano no reproduce su vida se muere, por ello la satisfacción de las necesidades es el límite más allá del cual no podemos ir. Así, el autor nos propone un principio para juzgar la factibilidad de todas nuestras acciones y proyectos de vida (el principio empírico de imposibilidad). Si un proyecto de vida o una institución contradice o impide la reproducción y crecimiento de la vida será perverso. Por ello la ética comienza cuando afirmamos la vida y negamos la muerte.
\end{abstract}

Palabras clave: Ética, Principio de imposibilidad, Factibilidad.

ABSTRACT: The one stops Hinkelammert the human action this limited one for several environments, the economic one, the politician, the technological one, etc., but ultimately this limited one for the satisfaction of the necessities. Since an if the human being doesn't reproduce his life he dies, for it the satisfaction of the necessities the limit beyond which we cannot go. This way, the author proposes us a principle to judge the feasibility of all our actions and projects of life (the empiric principle of impossibility). If a project of life or an institution contradicts or it impedes the reproduction and growth of the life will be perverse. For it the ethics begins I go a long way we affirm the life and we deny the death.

KEY WORDS: Ethics, Principle of impossibility, Feasibility.

\footnotetext{
*Facultad de Filosofía y Letras-UNAM (diogenesal@hotmail.com).
} 


\section{INTRODUCCIÓN}

\section{Presupuestos éticos y metodológicos}

Franz Hinkelammert tiene un extenso trabajo en el que los temas de economía, filosofía y teología son los más recurrentes; ha participado en publicaciones conjuntas sobre América Latina, la teoría de la dependencia y la globalización. No obstante, de todos los trabajos del autor destaca uno de ellos: Crítica a la razón utópica. Este libro aparece en 1984 publicado por el Departamento Ecuménico de Investigaciones de San José Costa Rica. El texto tiene la virtud de exponer lo que podemos considerar los presupuestos metodológicos de Franz Hinkelammert. En él recoge artículos y reflexiones hechas durante su estancia en la URSS allá por los años cincuenta del siglo xx y que debido a las circunstancias sociales y políticas sólo hasta este momento se dan a conocer en Latinoamérica, ${ }^{1}$ acompañan a este texto reflexiones más recientes sobre Economía política, Filosofía y Teología. Crítica a la razón utópica es un texto que se viene construyendo en un proceso complejo a lo largo de los años y da cuenta de la madurez del pensamiento de Hinkelammert.

Es un trabajo que alcanza un alto grado de abstracción y de sistematización, rigurosamente elaborado que no deja cabos sueltos y que aborda temas muy complejos. Expone uno de los temas más importantes y más difíciles de la filosofía política contemporánea: el tema de las utopías, que sobra decirlo es uno de los principales temas que hoy en día tiene una urgencia y necesidad primordial.

Hinkelammert realiza una crítica a todo el pensamiento utópico occidental y en particular a sus corrientes contemporáneas más importantes, es una crítica trascendental a la manera kantiana, que busca revelar

\footnotetext{
${ }^{1}$ Al respecto puede consultarse el capítulo "el marco categorial del pensamiento soviético contemporáneo". Cuenta Hinkelammert que en su momento no pudo dar a conocer en su totalidad este trabajo, ya que se publicó sólo una parte del mismo, pues la misma institución que financiaba el proyecto le censuró la parte fundamental en que hacía críticas al modelo soviético. El texto tuvo que esperar cerca de 30 años para su publicación.
} 
los marcos categoriales últimos desde los cuales se construyen tales utopías. De hecho en este trabajo se incluye el texto sobre "el marco categorial del pensamiento soviético", en el que literalmente se adelanta a su tiempo, ya que plantea una crítica al "socialismo real" que más tarde la encontraremos en la crítica hecha por la Perestroika. ${ }^{2}$

Hinkelammert como los buenos teóricos desarrolla una visión del mundo contemporáneo que le permite prever y detectar los problemas fundamentales de los seres humanos. Es un autor que indudablemente se adelanta a su tiempo y nos plantea una radiografía del mundo actual, pero es ignorado por las grandes instituciones filosóficas del primer mundo, claro como vive en el Tercer Mundo y escribe en español queda fuera de las grandes discusiones. ${ }^{3}$ Es sólo diez años después cuando su trabajo comienza a difundirse.

La crítica que propone Hinkelammert es de carácter marxista y está dirigida a los principales pensamientos contemporáneos y a sus modelos utópicos, lo que lo llevará a proponer una interpretación novedosa de la filosofía misma. ${ }^{4}$

Analiza el neoconservadurismo, el anarquismo, el neoliberalismo, el socialismo real y termina el texto con un apartado sobre Teología de la Liberación a la luz del pensamiento crítico; en general realiza la crítica del anti utopismo y la falsa utopía. ${ }^{5}$ El objetivo del autor es mostrar las incon-

${ }^{2}$ El autor hace notar que el proyecto socialista se desvió de sus objetivos e hizo del proyecto de liberación una forma más de dominio sobre el ser humano al convertir la tasa de crecimiento en el único criterio olvidándose de las necesidades humanas.

${ }^{3}$ En la Facultad de Filosofía y Letras de la UNAM es Enrique Dussel, quien se encarga de difundir su pensamiento cuando en 1992 propone en su seminario de Filosofía política la lectura de Crítica a la razón utópica. A invitación de Enrique Dussel se incorpora a las discusiones con los filósofos franckfurtianos K. Apel y J. Habermas. A partir de entonces la misma Europa comienza a abrirse al diálogo con el Tercer Mundo.

${ }^{4}$ De hecho lo que realmente hace Hinkelammert es retomar la propuesta de Marx modificando algunos aspectos pero manteniendo el núcleo de su reflexión en el ser humano.

${ }^{5}$ En otros libros Hinkelammert se encarga de la crítica a la llamada postmodernidad, así como al pensamiento de Max Weber. Al respecto pueden consultarse los libros Cultura de la esperanza y sociedad sin exclusión, El mapa del emperador, El grito del sujeto, Totalitarismo y democracia, así como El huracán de la globalización, editados por el Departamento Ecuménico de Investigaciones de San José, Costa Rica. 
sistencias no sólo lógicas, sino principalmente empíricas en las que caen dichas propuestas. Destruye los presupuestos sobre los que se estructuran y hace notar las contradicciones de las propuestas. Nos advierte que los autores de dichos modelos han caído en la ilusión trascendental — que es intentar como posible de alcanzar a largo tiempo el modelo idealizado-. Es el caso del neoliberalismo que intenta lograr el equilibrio perfecto del mercado por medio de la competencia, y en la búsqueda de esa ilusión sacrifica a los seres humanos. Nos dice Hinkelammert que intentar lo imposible como si fuera posible es rebasar el marco de la realidad. El objetivo es delimitar el campo de lo posible para la acción humana del campo de lo imposible.

Ese trabajo podría haberse titulado también "sobre lo imposible y lo posible", ya que es a partir de la imposibilidad como principio, que el autor realiza el análisis de los modelos de imposibilidad de las ciencias sociales. Nos dice Hinkelammert que lo imposible tiene un papel importante en el nivel epistemológico y práctico, ya que es a partir de la conceptualización de lo imposible como aparece el marco de lo posible. Por ello uno de los aportes fundamentales de nuestro autor es el principio general empírico de imposibilidad.

\section{EL PRINCIPIO EMPÍRICO DE IMPOSIBILIDAD}

\section{La crítica a Popper desde Popper}

En el capítulo V de Crítica a la razón utópica, Hinkelammert presenta la crítica de Karl Popper a los modelos de planificación perfecta, competencia perfecta institucionalización y a sus respectivas teorías, luego analiza la metodología de Popper. Estos modelos son imposibles, porque, señala Hinkelammert suponen ciertas imposibilidades para su realización, como es el caso del modelo conservador de Peter Berger que nos lleva a un control perfecto sobre la sociedad, el neoliberalismo porque presupone la competencia perfecta etc. Estas imposibilidades Popper las 
caracteriza como Principios de Imposibilidad que Hinkelammert va a desarrollar hasta sus últimas consecuencias, como veremos enseguida.

Popper nos dice que estos Principios de Imposibilidad son de carácter lógico. Por ejemplo es lógicamente imposible el control total de una sociedad, porque cada nueva relación de control es una nueva relación a controlar, y así sucesivamente hasta el infinito. Veamos otro ejemplo: es imposible el anti-intervencionismo total (en economía por ejemplo) porque toda nueva acción de desintervención es de suyo una intervención y así sucesivamente. Por lo tanto es imposible lógicamente concebir el anti-intervencionismo total (como pretende el neoliberalismo o la planificación total del socialismo real). ${ }^{6}$

Nos dice Popper que los Principios de Imposibilidad son los que delimitan la esfera de la ciencia y la metafísica. La esfera de la ciencia delimitada por los Principios de Imposibilidad (PI), es la esfera de las leyes y las teorías que se someten a la teoría de la falsabilidad, ${ }^{7}$ y la esfera de la metafísica es la esfera de las pseudo-teorías, de los sueños y de las utopías. Para Hinkelammert este descubrimiento de los Principios de Imposibilidad es fundamental. Señalan los límites de toda acción humana posible y permite destruir la ilusión trascendental. Pero a diferencia de Popper, para Franz estos PI no son de imposibilidad lógica, sino de imposibilidad empírica, por ello los PI que Popper llamaría Principios Generales Lógicos de Imposibilidad, Franz Hinkelammert los llama Principios Generales Empíricos de Imposibilidad o Principios Empíricos Generales de Imposibilidad (PEGI-PI).

${ }^{6}$ Cfr. Franz Hinkelammert, Crítica a la razón utópica, San José, Departamento Ecuménico de Investigaciones (DEI), 1984, pp. 275.

${ }^{7}$ Para Popper la falsabilidad designa la posibilidad que tiene una teoría de ser desmentida, falseada o "falsada" por un hecho determinado o por algún enunciado que pueda deducirse de esa teoría y no pueda ser verificable empleando dicha teoría. Toda verdadera teoría científica tiene que ser sometida a este proceso de verificación. "La Validez de las teorías científicas descansa sobre enunciados falsables y que solamente éstos pueden garantizar el status científico de tales teorías". Enunciados seguros supondrían conocimientos totales. Ibid., p. 159. 
Es importante aclarar esta distinción ya que contiene implicaciones fundamentales para nuestro autor. Los PEGI son juicios empíricos, categóricos, apodípticos, no falsables, de validez científica, lógicamente posibles, fácticamente imposibles, contrastables y evaluables. El hecho de que los PEGI no sean falsables empíricamente es de una gran importancia metodológica, ya que permite a Hinkelammert poner en duda la teoría de la falsación de K. Popper, asunto que no puede resolver el mismo Popper. El problema es: los PI tienen validez científica y por lo tanto la teoría de la falsabilidad queda cuestionada como teoría general, o se mantiene la teoría y los PI no tienen validez científica perdiéndose todo criterio de demarcación y cuestionándose toda la teoría de la ciencia de Popper, lo que va a cuestionar a su vez la teoría de la falsabilidad.

Para resolver este problema Hinkelammert estudia los posibles falsadores de los PI, descubriendo que son imposibles empíricamente, pero que lógicamente son posibles. Son los mismos Principios de Imposibilidad (PI) pero expresados positivamente.

$\square$ PI. Es imposible que un hombre construya un perpetuum mobile.

Falseador: éste es un perpetuum mobile.

$\square$ PI. Es imposible un hombre inmortal.

F: Éste es un hombre inmortal.

$\square$ PI. Es imposible que un hombre viva sin alimentos.

F: Este hombre vive sin alimentos.

$\square$ PI. Es imposible que un hombre tenga conocimientos ilimitados.

F: Este hombre tiene conocimientos ilimitados.

$\square$ PI. Es imposible un hombre para el que no valga la discursividad en el tiempo.

F: Este hombre se mueve en el tiempo según su voluntad. 
PI. Es imposible un hombre para el que no valga la discrecionalidad en el espacio.

F: Este hombre se mueve según su voluntad instantáneamente en el espacio y puede estar en varios lugares a la vez. ${ }^{8}$

Estos falsadores son imposibles empíricamente. Pero son posibles lógicos, describen el conjunto de los mundos metafísicos, y bien señala Hinkelammert fundan todo mundo trascendental posible. Son los mismos PI pero presentados positivamente, lo cual les da su carácter trascendental. Hinkelammert los llama falsadores trascendentales.

De hecho, estos falsadores trascendentales trascienden el marco de la teoría de Popper, para quien los falsadores o enunciados básicos son hechos observables en el tiempo y el espacio que falsean una teoría o ley.

Por ello la teoría de la falsabilidad de Popper no puede dar cuenta de los PEGI y sus falsadores trascendentales, ni de las leyes empíricas generales. Habría entonces dos tipo de inducción, dos tipos de falsadores y dos tipos de leyes de la ciencia. Al declarar Popper todos los enunciados científicos como falsables no puede ya admitir la existencia de imposibilidades apodícticas, ${ }^{9}$ a no ser como contradicción de la lógica formal. Por ejemplo el enunciado los seres humanos no pueden vivir sin alimento es un hecho demostrativo que no admite contradicciones. Popper no puede ver eso ya que no acepta los enunciados no falsables por ello cae en contradicción.

Pero Hinkelammert continúa con su crítica a Popper, los PI delimitan dos mundos: el de la ciencia y el de la metafísica. Pero Hinkelammert ya ha mostrado cómo el mundo de la ciencia tiene tanto un componente empírico como uno trascendental delimitado por los PI. Lo que realmente demarcan los PEGI son el mundo de lo trascendental del mundo de lo empírico, o dicho en otros términos: el mundo de lo posible y de lo imposible. Si Popper ha caracterizado el primero como metafísica, pues la ciencia tiene su componente metafísico ineludible. Popper ha quedado en el

\footnotetext{
${ }^{8}$ Cfr. Hinkelammert, op. cit., p. 275.

${ }^{9}$ Cfr. Ibid., capítulo IV.
} 
segundo nivel en su teoría particular, que de paso ha dado los propios elementos para trascenderla.

Después de esta explicación un tanto apresurada de la crítica a Popper, Hinkelammert aborda el tema de las utopías pero retomando los PEGI del tema anterior. Nos dice que el mundo de las utopías es también el mundo de lo imposible, de los modelos ideales de la ciencia e incluso el mundo de la trascendencia teológica, aunque todas esas determinaciones presentan sus necesarias diferencias categoriales. El mundo de lo trascendental no es entonces estigmatizable; es algo necesario e inevitable para el ser humano.

El ser humano tiene una tendencia ontológica a trascender su entorno. Esto es, a transformar la naturaleza o la sociedad, no sólo porque tenga objetivos que realizar sino, principalmente, porque él es un sujeto con necesidades qué satisfacer. Y es por medio de esa transformación que puede satisfacerlas. Es un ser de la praxis, pero su actuar no es una acción libre de condicionamientos, es más bien acción limitada, aunque no absolutamente limitada. En su accionar el ser humano busca trascender su realidad, ${ }^{10}$ pero se da cuenta de que está sometido a ella, así su accionar está limitado por el marco de lo posible. Dicho marco nos muestra lo que se puede y lo que no se puede hacer, de no existir este marco de lo posible, no cabría hablar de un límite para la acción humana y ésta no estaría sometida a la realidad. Entonces, estaríamos hablando del sujeto absolutamente libre de Descartes. Pero por otra parte, si no existiera la posibilidad de trascender lo dado, no sería posible pensar en una transformación de lo existente, que socialmente es opresor la mayoría de las ocasiones. Esto es, no podríamos pensar en cambios sociales y tendríamos que acoplarnos y conformarnos con un sistema injusto.

[...] el trascender lo posible (la realidad) es condición para conocer lo posible $\mathrm{y}$, a su vez, conocer lo posible es condición para trascender la realidad en el marco de lo posible. ${ }^{11}$

${ }^{10}$ El hombre moderno así como la ciencia durante mucho tiempo se han comportado como si fueran "los dueños del mundo" y han expoliado destruyendo el entorno sin ninguna restricción.

${ }^{11}$ Hinkelammert, op. cit., p. 232. 
El problema es, pues, buscar los marcos o límites a partir de los cuales el sujeto puede actuar, sin tratar de realizar algo que está más allá de sus posibilidades reales. Así, el sujeto reconoce a) una realidad que existe independientemente de él y b) que le marca límites en su accionar. Es este reconocimiento de la realidad que va más allá del sujeto lo que le permite a Franz Hinkelammert superar posturas idealistas tan presentes en la ciencia moderna. Esto hace que la propuesta del autor esté siempre en tierra firme.

Pero como el sujeto ${ }^{12}$ tiene una tendencia natural al conocimiento, está en busca constante de nuevos conocimientos que le permitan transformar su entorno.

Así, el sujeto formula proyectos que trata de realizar, pero el realizar dichos proyectos implica trascender lo dado. El interés por trascender lo dado lo lleva a aspirar a conocer la totalidad, lo cual es imposible, por ello recurre a la elaboración de conceptos o categorías universales que le permiten trascender la empíria y "superar" las limitaciones propias del ser humano. ${ }^{13}$ De hecho así es como se elaboran las teorías científicas, pero son de carácter hipotético, ya que no son más que una construcción del sujeto y muchas veces no son consistentes. Lo que sucede es que el sujeto nunca logrará conocer la totalidad de lo real, por el principio de imposibilidad: "es imposible una persona con conocimiento perfecto o ilimitado". Los Principios de Imposibilidad nuevamente actúan para delimitar el campo de lo posible. Los conceptos universales trascienden toda experiencia posible, pero a su vez son trascendidos por la realidad..$^{14}$

12 Para Hinkelammert la categoría sujeto tiene una connotación más específica que está ligada a la lucha por la vida. Desarrolla esta idea en uno de sus trabajos más recientes $E l$ grito del sujeto. Nos dice Hinkelammert que sólo es sujeto el que puede afirmarse como tal al negar el sistema, al respecto puede consultarse el apartado final de este trabajo.

${ }^{13}$ El interés que mueve al ser humano a conocer y transformar la realidad, no es un mero interés cognoscitivo, sino más bien es un interés vital. Marx decía que el ser humano al transformar la naturaleza se transforma a sí mismo por medio del trabajo, es decir desarrollaba sus capacidades tanto físicas como intelectuales, en una palabra se constituía a sí mismo como ser humano, se humanizaba. Hinkelammert sigue a Marx en este punto.

${ }^{14}$ Cfr. Hinkelammert, op. cit., capítulo IV. 
De lo contrario estaríamos diciendo que la parte es igual al todo. Es decir, el ser humano sólo puede tener acceso a un número determinado de casos y a partir de las observaciones realizadas construye conceptos de alcance universal que "den cuenta de todos los casos posibles", pero a su vez estos conceptos universales son (superados) trascendidos por la realidad.

Al igual que los conceptos universales, las teorías científicas son igualmente hipotéticas ${ }^{15} \mathrm{y}$ trascendidas por la realidad. Pero si seguimos la regla de que "toda teoría científica es hipotética", tendríamos que el enunciado "la realidad trasciende a las ciencias" es también hipotético, con lo cual caeríamos en un círculo vicioso. Como aquella vieja discusión de los filósofos acerca de la existencia de términos absolutos — si afirmas que no existen términos absolutos entonces tu misma afirmación es de hecho un absoluto-. Hinkelammert resuelve este problema al hacer la distinción entre dos tipos de hechos: aquellos que pueden ser falsables y los hechos fundantes.

Hechos fundantes (o meta hechos) cuya afirmación no es falsable, y hechos cuya afirmación es falsable y por tanto, hipotética.

Los hechos fundantes, son afirmados por Principios de Imposibilidad; constituyen el ámbito de los hechos hipotéticamente afirmados. Pero como tales los hechos fundantes constituyen el punto de partida de la deducción de leyes generales de las ciencias empíricas. ${ }^{16}$

Por ello, el enunciado "la realidad trasciende las teorías científicas y al sujeto" es un hecho categórico no falsable, de lo contrario sería posible la existencia del sujeto fuera de la realidad, es decir, trascendente. El principio de imposibilidad "es imposible que un sujeto viva por fuera de la historia y de la realidad" sería falsable empíricamente.

${ }^{15}$ Ibid., p. 234. Hinkelammert nos dice que "el pensamiento teórico aborda la realidad por medio de teorías. "Siendo estas teorías necesariamente inseguras, teorías seguras suponen el conocimiento de todos los hechos "lo cual es imposible empíricamente".

${ }^{16}$ Ibid., p. 236. 


\section{LOS PRINCIPIOS DE IMPOSIBILIDAD: ÉTICA Y SUJETO}

Tenemos un primer hecho fundante "la realidad trasciende al sujeto y le marca límites para su acción”. Pero también existe otro hecho fundante, que es "la subjetividad del ser humano trasciende las determinaciones del sujeto", lo que Hinkelammert quiere señalar es que el ser humano no se agota en las determinaciones del sujeto, sino que es una plenitud que está más allá de las determinaciones que le impone la institucionalidad al sujeto, tiene un carácter simbólico.

El mundo moderno hace del sujeto uno de sus conceptos centrales, pero no capta lo fundamental del problema. La ciencia y ciertas filosofías modernas ${ }^{17}$ tienen una idea de sujeto que está atravesada por un enfoque formalista que empobrece la noción de sujeto. Veamos un ejemplo breve: para las grandes compañías transnacionales no somos más que potenciales consumidores, trabajadores mal preparados, mano de obra barata o en el peor de los casos somos estorbos o deshechos de la sociedad que se deben eliminar.

En esta misma línea, Hinkelammert nos dice que la persona — el sujeto vivo - trasciende todas las determinaciones (reducciones) que el sistema, la ciencia o las teorías científicas hacen de él, el lenguaje, los medios de difusión, los políticos, etc., distorsionan la noción de sujeto. El ser humano es tematizado como un sujeto cognoscente dentro de un paradigma de la conciencia que no es más que una visión del sujeto como un no-vivo. Como dice Germán Gutiérrez

El ser humano es interpretado (como) un sujeto trascendental de todo conocimiento y enunciado, que prescinde de toda corporalidad y concretud histórica, y se sitúa ante el mundo en condición de observador imparcial y no involucrado. ${ }^{18}$

${ }^{17}$ Pienso en una filosofía como la de Emmanuel Kant, el Racionalismo de Descartes y el Empirismo de Hume por una parte y por otra en los economistas clásicos como Adam Smith, David Ricardo que perfilaban al ser humano de manera formal-abstracto.

${ }^{18}$ Germán Gutiérrez, Ética y economía en Adam Smiht y Friederich Hayek, México, Universidad Iberoamericana, 1996 (Tesis de Maestría publicada por el Departamento Ecuménico de Investigaciones, San José, 1998). p. 29. 
Hinkelammert va a demostrar que la persona — el sujeto vivo- es la condición de posibilidad (condición necesaria) para la existencia de cualquier tipo de manifestación posterior del sujeto. Es decir, detrás del sujeto cognoscente de las ciencias está el sujeto vivo con necesidades.

Como se trata de un sujeto con necesidades debe actuar con la intención de transformar su entorno (la realidad) para obtener los bienes que satisfagan sus necesidades. Por ello el ser humano se transforma en un sujeto actuante y reflexivo. Este sujeto actuante y reflexivo sólo puede actuar a partir de los límites que le marca la realidad. Por ello la actuación del sujeto está sometida al marco que le impone la realidad, de esta manera el sujeto construye fines de acción, que a su vez se inscriben en proyectos de alcance mayor.

Sin embargo nos advierte Hinkelammert, del conjunto de todos los fines posibles el ser humano sólo tiene acceso a un número determinado de ellos, no a todos los fines. Y a su vez de ese número determinado de fines el sujeto sólo puede elegir un subconjunto de los fines posibles, ya que se enfrenta a un nuevo límite que le marca la realidad, el límite de la escasez de medios para la realización como condicionante material de toda elección. Ilustremos este caso por medio de un ejemplo: supongamos que nuestro fin es difundir el conocimiento y enseñar a leer a todos los niños y jóvenes del país; nuestro fin choca con límites que le marcan las condiciones materiales, ya que no existen medios materiales (y económicos) para fabricar todos los libros y cuadernos necesarios para lograr dicho fin. Por otra parte harían falta también las instalaciones en las cuales se pueda realizar dicho proyecto, salvó algunas excepciones es difícil enseñar a leer si no tenemos instalaciones adecuadas, aún más necesitaríamos de un inmenso número de voluntarios y voluntarias que nos ayuden en nuestra campaña.

Para trascender lo dado, habíamos dicho, el sujeto recurre a la ciencia, éste abstrae una parte de la realidad que la convierte en empíria, la ciencia se vuelve tecnología para hacer posibles dichos proyectos. Pero ahí se da cuenta que de los proyectos tecnológicamente posibles no todos se pueden realizar, ya que están delimitados a su vez por el ámbito de lo eco- 
nómico. Es decir, cualquier proyecto que se pretenda realizar sea o no tecnológico, necesita de condiciones materiales - y económicas - para su realización. Así, los proyectos tecnológicamente posibles se vuelven a su vez económicamente posibles, en cuanto pueden ser realizados en este nuevo ámbito.

Ningún proyecto puede realizarse si no es materialmente posible, y la voluntad no puede sustituir jamás las condiciones materiales de posibilidad. ${ }^{19}$

El marco de los proyectos económicamente posibles es menor que el de los proyectos tecnológicamente posibles. Así este marco impone un límite al de los proyectos tecnológicamente posibles. Se puede dar el caso que un proyecto sea tecnológicamente posible pero a su vez no ser factible económicamente, ejemplo el transplante de hígado es tecnológicamente posible, sin embargo en los países del Tercer Mundo para la gran mayoría de su población es económicamente imposible.

Hinkelammert va más allá y nos dice que el marco de los proyectos económicamente posibles choca a su vez con un nuevo límite, el límite que impone la política. Aunque dicho límite no es desarrollado por Franz, si nos da material suficiente para presuponerlo. Ese límite no debe ser entendido como límite que nos marca el Estado o la institucionalidad, sino como el derecho que tiene(n) la(s) persona(s), los grupos o las etnias, es una forma de reconocimiento de la dignidad de las personas y podríamos decir que es una forma de la razón ética originaria de la filosofía de la liberación de Dussel.

Lo ético-político tiene a su vez otro límite; el que impone la naturaleza. Tampoco este límite es considerado en este escrito (Crítica a la razón utópica), pero lo va a desarrollar en otros de sus escritos. ${ }^{20}$ Los

${ }^{19}$ Hinkelammert, op. cit., p. 238.

${ }^{20}$ Nos dice Hinkelammert en el Mapa del emperador que el ser humano se ha olvidado que entre él y la naturaleza existe una relación de dependencia y lo que el ser humano haga a la naturaleza se lo hace a sí mismo, de tal forma que al destruir el entorno natural se está destruyendo a sí mismo. No existe la naturaleza por un lado y el hombre 
proyectos que son factibles ético-políticamente no son realizables del todo si entran en contradicción con el nuevo límite que impone la naturaleza. Es imposible empíricamente trascender la naturaleza, por el Principio de Imposibilidad (PI) "es imposible la existencia de una persona por encima de la naturaleza". Hinkelammert nos recuerda las palabras del jefe indio Seattle pronunciadas en 1855 frente a representantes del gobierno de Estados Unidos, cuando el genocidio de los habitantes originarios del norte de América era previsible.

Nosotros sabemos esto: la tierra no pertenece al hombre. El hombre pertenece a la tierra. Nosotros sabemos, esto: todas las cosas están relacionadas, como la sangre que une a una familia. Todas las cosas están interrelacionadas entre sí. Todo lo que sucede a la tierra, sucede a los hijos de la tierra, sucede a los hijos de ella. El hombre no trama el tejido de la vida. Él es, sencillamente, una pausa en ella. Lo que él hace a ese tejido, lo hace a sí mismo. ${ }^{21}$

Cualquier proyecto posible está planeado sobre el ámbito de la naturaleza, y por tanto, el ser humano debe respetar y tomar en cuenta este ámbito para cualquier proyecto posible. La sociedad moderna al guiarse por la racionalidad medio-fin no respeta dicho límite y termina talando el árbol sobre el que está subida la humanidad, con el consiguiente peligro de acabar con la humanidad entera. Es, pues, este límite ecológico el que impone y reduce el actuar del ser humano una vez más.

Una vez más la acción humana se enfrenta a un nuevo límite: el de "los proyectos". El ser humano no sólo tiene fines en sí, porque se ocurren, todo fin está inscrito de una manera o de otra en un proyecto, cualquiera que éste sea. Hinkelammert reflexiona sobre los fines y los

por el otro, ambos se implican y se necesitan. Hinkelammert siguiendo a Marx dice que las dos fuentes de la riqueza son: por un lado la naturaleza y por el otro el ser humano, pero la sociedad moderna capitalista las ha puesto en peligro.

${ }^{21}$ Véase Diálogo Social, núm. 154, Panamá, 1983. Citado en "El cálculo de utilidad y la creación del infierno en la Tierra" de Franz J. Hinkelammert en La filosofía crítica de Franz Hinkelammert. Antología, vol. I preparada por José Manuel Arellano sin publicar, 2001 p. 209. El artículo también aparece en la revista Ambientico, núm. 99, San José, diciembre, 2001. 
medios, se suele decir que "el fin justifica los medios". Se pregunta el autor y ¿quién va a justificar los fines? Entonces tenemos que los mismos fines están supeditados a ser compatibles con algún proyecto de vida posible, y los fines que no permiten realizar dicho proyecto de vida no deben realizarse.

En efecto, dado que únicamente un sujeto vivo puede proyectar y realizar fines, la elección de éstos necesariamente está subordinada a la vida del sujeto. En consecuencia, no todos los fines concebibles técnicamente y realizables materialmente según un cálculo medio-fin, son también factibles; sólo lo es aquel subconjunto de fines que se integran en algún proyecto de vida. Es decir, fines que no son compatibles con el mantenimiento de la vida del sujeto mismo caen fuera de la factibilidad. Cuando se realizan acaban con la vida de aquel que los realiza con el resultado de que ya no se pueden realizar más fines. ${ }^{22}$

Cuando se conciben los fines únicamente desde el ámbito medio-fin y se olvida la interconexión que existe con otros ámbitos de la sociedad, se termina por verlo como un asunto meramente práctico. Por el contrario todo fin, nos dice Hinkelammert, está inscrito en algún subconjunto de fines y medios más amplios y a su vez, todos ellos forman parte de un proyecto de vida (el proyecto de vida tiene como medio para su realización estos fines parciales).

En la época moderna existe la tendencia dominante a considerar las cosas desde una perspectiva medio-fin en la que lo único que guía al actor es lograr la meta o el fin deseado con el menor esfuerzo y la máxima ganancia. Esta actitud da lugar a la formación de la idea de una aparente neutralidad valorativa en la que el autor puede escoger cualquier medio que desee para lograr su objetivo. Pensemos en un ejemplo sencillo: el fabricante de muebles calcula su acción a partir del número de árboles talados por día, de tal manera que si su objetivo es incrementar sus ganancias, debe incorporar nuevas herramientas con las cuales se eleve el número de árboles talados por día. El fin propuesto se logró,

${ }^{22}$ Hinkelammert, Crítica a la razón utópica ..., pp. 239-240. 
por lo tanto la acción — de acuerdo con la racionalidad instrumentalfue correcta. Sin embargo, como resultado de ello aumentó el nivel de desertificación en los bosques, pero eso no lo puede ver.

Hinkelammert nos dice que todos estos fines sólo tienen sentido cuando los vemos desde la perspectiva de algún proyecto de vida. El sujeto no actúa separado del mundo, de la realidad, sino que está actuando desde un proyecto de vida determinado. En el caso del fabricante de muebles, si su proyecto de vida es vivir de su trabajo, entonces deberá reconsiderar y no talar todos los árboles indiscriminadamente, pues destruye el medio de vida de otras personas y el suyo propio.

Al final de la cita anterior Hinkelammert indica que "sólo es factible aquel subconjunto de fines que están integrados a algún proyecto de vida". Todo sujeto que pretenda vivir constituye de una manera o de otra algún proyecto de vida, ${ }^{23}$ pues sólo de esa manera es posible vivir. A menos que el sujeto decida morir entonces estará en condiciones de elegir libremente cualquier fin. Pero...

Renunciando al suicidio, aparece un marco de factibilidad de fines que está dado por algún proyecto de vida que enjuicia todos los fines en relación a su factibilidad. La decisión de vivir según algún proyecto de vida y que se concreta a través de los fines hacia los cuales el sujeto se encamina, enjuicia los fines y los somete a una racionalidad de vida ${ }^{24}$ que no permite una simplista neutralidad valórica. Luego, los fines no son neutrales sino que son los vehículos de la vida del sujeto, el cual ni siquiera puede perseguir fines sin la realización de su proyecto de vida. ${ }^{25}$

Pero no cualquier combinación de fines puede ser realizable, pues deben permitir la realización de algún proyecto de vida. Siendo el sujeto

${ }^{23}$ Desde el punto de vista de la ética se dice que una persona se constituye como tal en el momento en que es capaz de dar forma a un proyecto de vida y deja atrás su naturaleza puramente instintiva. La vida humana aparece como vida que tiene un sentido, y ese sentido de la vida lo obtiene del proyecto de vida.

${ }^{24}$ Para Hinkelammert la vida debe tener un sentido racional, no se trata de la simple vida animal, sino de una vida orientada por la razón, que abarca un momento material y también un momento espiritual. Como dice Marx se trata de vivir humanamente.

${ }^{25}$ Hinkelammert, Crítica a la razón utópica..., p. 240. Las cursivas son mías. 
un ser natural, cualquier elección de fines debe preguntarse y ajustarse a las condiciones naturales de cualquier proyecto de vida. Siendo el ser humano un ser vivo está enfrentado a este marco de factibilidad en el cual construye proyectos de vida.

Los fines no son del todo elegibles de acuerdo al gusto del ser humano. Pensemos un momento en algunos proyectos de vida con la intención de analizar las implicaciones sociales que dichos proyectos presuponen.

Pensemos en primer lugar en el proyecto de vida de un piloto de la fuerza aérea de Estados Unidos, esta persona sueña que llegado el momento de una guerra matará a muchos soldados enemigos, ganará un ascenso y una recompensa monetaria.

Por otra parte podemos pensar en el proyecto de vida de un empresario que se dedica a fabricar muebles de madera. Esta persona espera obtener maquinaria cada vez más moderna que le permita talar más rápido el bosque con lo cual disminuirían sus costos de fabricación para incrementar sus ganancias.

El proyecto de vida de un profesor universitario especialista en las Humanidades.

Finalmente podemos mencionar el proyecto de vida de la madre Teresa de Calcuta que buscaba ayudar a los necesitados y a los enfermos.

Nuestro ejercicio consiste en reflexionar sobre la pertinencia de estos diversos proyectos de vida, los cuales nos van a permitir avanzar en nuestra argumentación.

Es claro que los dos últimos ejemplos tienen un mayor compromiso social con la comunidad, pues son de carácter colectivo mientras los dos primeros casos son contrapuestos al bienestar social. De hecho los dos primeros casos se inscriben en lo que podemos llamar la política del verdugo, el cual sólo puede ver realizado su proyecto de vida cuando eliminan otro. Cuando el actor realiza un buen trabajo aparecen víctimas de su acción. En el primer caso el que sufre es el otro pueblo, ${ }^{26}$ su proyecto de vida es, pa-

${ }^{26}$ Utilizo la palabra pueblo en lugar de país porque en las guerras los que sufren son las personas de carne y hueso, y no un país. En términos de la ética de Hinkelammert, la 
radójicamente, proyecto de muerte. En el segundo caso es algo similar, porque quien sufre en este caso es la naturaleza, y en segundo momento las personas de la comunidad que ven dañado su medio ambiente.

Descubrimos entonces que existe una gran variedad de proyectos de vida de diversos tipos y géneros, aún más, existen proyectos de vida que se contradicen unos a otros, que se excluyen. Pero el asunto tiene más telas que una cebolla, y así, encontramos que dichos proyectos de vida tienen un límite más, pues no son del todo elegibles, sino que siendo el ser humano un ser vivo con necesidades qué satisfacer, todo proyecto de vida debe basarse en la satisfacción de las necesidades del sujeto, Hinkelammert tiene presente este límite, de tal forma que nos advierte que los proyectos de vida deben tomar en cuenta la satisfacción de las necesidades del ser humano. Este ser vivo que actúa en este marco de factibilidad debe cumplir con una exigencia básica: la satisfacción de las necesidades.

En efecto para vivir hay que poder vivir, y para ello hay que aplicar un criterio de satisfacción de las necesidades a la elección de los fines, siendo el sujeto un ser natural esta satisfacción de necesidades tiene una raíz insustituible basada en la propia naturaleza humana. Sea cual sea el proyecto de vida, éste no puede realizarse si no se asegura los alimentos para vivir, vestido, casa, etc. Pueden darse enormes variaciones en relación a estos elementos, pero no pueden faltar. ${ }^{27}$

referencia última son las personas, por ello la guerra está dirigida contra el pueblo no contra las instituciones, cuando yo digo por ejemplo "el país está sufriendo la falta de comida" - estoy haciendo una abstracción, hablo en lenguaje figurado - los que sufren son las personas no las instituciones que como tal no tienen vida. En estos años hemos sido testigos de la masacre al pueblo de Irak por parte de Estados Unidos y Gran Bretaña, poder que destruye a inocentes en nombre del mercado y los intereses petroleros.

${ }^{27}$ Hinkelammert, Crítica a la razón utópica..., p. 240. 
De nuevo Hinkelammert utiliza el principio de imposibilidad para determinar si una acción es posible o no. De esta manera nos señala el enunciado "es imposible la existencia de una persona que viva sin alimentos", no sólo es lógicamente imposible sino principalmente empíricamente imposible. Por ello surge ahora un criterio superior sobre los otros criterios anteriores: la satisfacción de las necesidades humanas. De esta manera el ser humano actúa con el objetivo de satisfacer sus necesidades. Pero debemos tener cuidado cuando hablamos de la satisfacción de necesidades, pues podría interpretarse desde un ámbito meramente biológico, no. Hinkelammert no lo piensa en ese sentido, esta satisfacción de necesidades se realiza desde una cultura determinada de acuerdo con las reglas de la cultura y con gusto culinario y estético, en una palabra como lo dice Marx, comer tiene un sentido espiritual. En un ámbito sociocultural, no es el mero comer animal.

Por medio de un esquema podríamos ejemplificar la propuesta del autor, veamos como podríamos presentarlo:

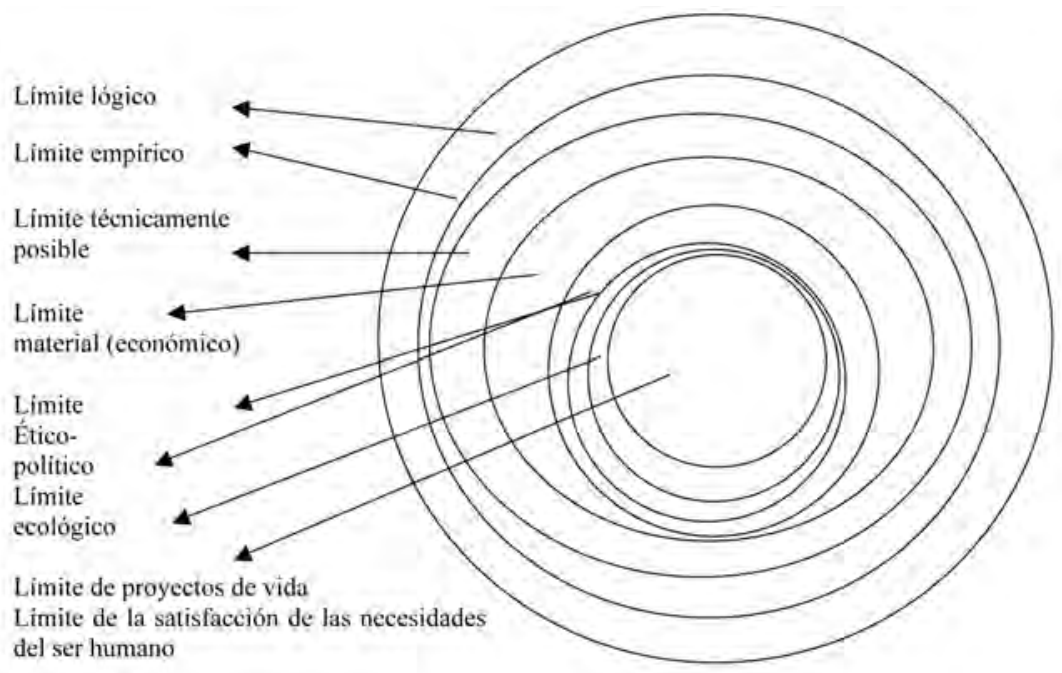


Como podemos ver cada uno de estos límites nos marcan el ámbito posible para la acción humana, pero cada uno de estos límites se encuentra a su vez con una nueva restricción que debemos tomar en cuenta. De tal manera que el límite que se debe respetar en última instancia es el de la satisfacción de las necesidades del ser humano. Toda acción del ser humano debe por lo tanto considerar este límite de la satisfacción de las necesidades, de lo contrario se corre el riesgo de hacer del ser humano una abstracción y perder el sentido de la vida. Para Hinkelammert, la realidad misma tiene este criterio de satisfacción de necesidades, pero veamos con detalle este problema en el siguiente apartado.

\section{LA ÉTICA Y EL CRITERIO VIDA-MUERTE}

\section{La ética para Franz J. Hinkelammert}

Frente a las éticas principialistas, Hinkelammert retoma a Carlos Marx y nos plantea una ética que se preocupa por los contenidos concretos más que por principios abstractos. Para nuestro autor la ética se inicia cuando hemos decidido afirmar la vida. Es decir, la ética se constituye en el momento en que nos decidimos a vivir. De tal manera que la ética está constituida desde un determinado horizonte. Este horizonte es la vida. Por lo tanto Hinkelammert apuesta por una ética de la vida. ${ }^{28} \mathrm{~A}$ partir del análisis de los trabajos de Carlos Marx, el autor recupera como principio central de la ética la vida del ser humano. Como sólo un ser vivo puede tomar decisiones, la condición de posibilidad para la existencia de la ética es la conservación de la vida.

Anteriormente se decía que el principal pecado era atentar contra Dios, pero si Dios ha muerto ya no hay pecado, entonces todo está per-

${ }^{28}$ Para Hinkelammert al igual que para Marx, el sistema capitalista actual tiene detrás de sí una ética de la muerte, ya que si yo obedezco a sus reglas llego a la muerte del sujeto. 
mitido. Hinkelammert nos advierte, hoy el pecado es atentar contra la vida. Existe un pecado fundamental y ése es el suicidio, porque con él se acaba la ética y se acaba la vida.

"El no suicidio es condición de posibilidad de la ética". Admitiendo el suicidio no hay manera de constituir una ética. ${ }^{29}$

Podríamos creer de acuerdo con Hinkelammert, que la vida es ahora el máximo valor que debemos preservar. Pero no es exactamente así. Veamos, la vida no es un valor en sí, sino más bien todo posible valor tiene como marco de referencia último a la vida. Debemos poner atención al hecho de no reducir la vida a una cuestión de valores, porque de lo contrario perderíamos el sentido de la crítica, pues es cuestión de valores nos dicen y como la valoración es subjetiva nunca nos vamos a poner de acuerdo.

Por el contrario veamos en qué consiste el argumento que nos dice Germán Gutiérrez discípulo de Hinkelammert:

Cuando consideramos a la vida como un valor o un derecho, ya de algún modo la estamos negando, o rebajando. La vida no tiene valor en el sentido de que no es medible, calculable, comprable o negociable. Está más allá de esa esfera de los valores morales. Es muy superior a todo valor, ni siquiera comparable con ningún valor. Es la fuente de todo valor. ${ }^{30}$

El marco de valoración nos aparece justamente desde la vida, nos es dado desde la afirmación de la vida y negación del suicidio. Al afirmar la vida me aparece todo un horizonte desde el cual puedo tomar decisiones, y con él una serie de posibilidades de acción, aunque también me aparece el marco de las imposibilidades. La afirmación de la vida aparece como el fundamento de la ética, ya que sólo si estamos decididos a

${ }^{29}$ Cfr. Diálogo con Franz Hinkelammert en la Facultad de Filosofía y Letras de la UNAM, 23 de noviembre, 1995 (versión grabada).

${ }^{30}$ Germán Gutiérrez, "Neoliberalismo y ética", en Neoliberalismo y sujeto rebelde: entre la lucha y la desesperanza, vol. I, Antología preparada por José Manuel Arellano sin editar, 2001, y en Revista Logos, núm. 79, ANUIES. 
renunciar al suicidio tiene sentido hablar de una ética. Para nuestro autor el ser humano debe reconocer que se encuentra enfrentado al problema de la vida-muerte. Esto es que sus acciones están enmarcadas en este horizonte de la vida-muerte a partir del cual debe relacionarse con el mundo, veamos con más detalle.

Este reconocimiento mutuo entre sujetos naturales y necesitados ${ }^{31}$ trasciende la relación mercantil para juzgarla. Trasciende igualmente el lenguaje. Este trascender ocurre desde el interior de las relaciones mercantiles como lenguaje. Sin embargo se enfrenta a ellos para darles su contenido real. Este contenido real, que enjuicia los esquemas formales del lenguaje y del mercado es a la vez subjetivo. Es el hecho de que el sujeto está enfrentado a la encrucijada de la vida y muerte, constituye esta realidad del mundo que se enfrenta al lenguaje y al mercado. Pero se trata de una subjetividad de validez objetiva, forzosa. El actor por fuerza tiene que entenderse como sujeto para poder vivir. Por eso los juicios de hecho, cuyo criterio de verdad es de vida y muerte, son a la vez los juicios constituyentes de la realidad objetiva. ${ }^{32}$

De la cita anterior podemos rescatar varias cosas primero: esta relación pasa por el reconocimiento del otro como persona igual a mí, - - Hinkelammert está en contra de los falsos reconocimientos de las personas- se debe respetar al otro porque es condición de posibilidad para que yo viva. Segundo: el ser humano se enfrenta al problema de vida y muerte, este problema no puede evadirlo ya que forma parte de su propia naturaleza humana. Tercero: este argumento pone al ser humano como el centro de toda la relación. Cuarto: el ser humano es el punto central y continua referencia de la realidad. Es decir existe una estrecha relación entre la vida del ser humano y la constitución de la realidad objetiva. Para nuestro autor la reali-

${ }^{31}$ El problema del reconocimiento entre sujetos es un tema central en la propuesta del autor, sin embargo por motivos de claridad en la exposición lo desarrollo en otro trabajo. Podemos adelantar un poco el tema, Hinkelammert dice que toda relación ética está constituida a partir del reconocimiento del otro sujeto, que al salvar al otro nos salvamos a nosotros mismos mejor, que lo que hacemos al otro lo hacemos a nosotros mismos. El otro es el criterio y el referente principal para Hinkelammert.

${ }^{32}$ Hinkelammert, El mapa del emperador..., p. 42. 
dad se constituye desde la vida del sujeto que está afirmando la vida. Por ello no es que la realidad y la vida del sujeto vayan por caminos separados, sino que entre ambos existe un estrecho vínculo, de tal manera que no se puede hablar de la realidad objetiva si no estoy afirmando o hablando de la vida del sujeto.

La objetividad de la realidad no antecede a la vida humana, sino que es tanto su producto como su presupuesto [...]. Los juicios de hecho, cuyo criterio de verdad es de vida y muerte, son constituyentes de la objetividad de la realidad en el mismo acto en el cual juzgan sobre ella. Por consiguiente, la objetividad es subjetiva, si bien el carácter subjetivo del actor es un hecho objetivo. La negación del sujeto, por ende, contradice a los hechos y hace imposible dar cuenta de la objetividad de la realidad a la vez. ${ }^{33}$

No tendría sentido hablar de una realidad o de un mundo sin seres humanos, pues caeríamos en abstracciones que escapan a esta postura realista para aproximarnos a una visión de corte metafísico. Pretender situarse en un horizonte tal es reducir todo a la res extensa de Descartes. Por ello insiste el autor en que toda la realidad gira entorno a la vida del ser humano. Esto podría parecernos como una especie de antropocentrismo; y sí en efecto, se trata de un verdadero antropocentrismo en el que el sujeto está en el centro, pero a diferencia del antropocentrismo de la moderni$\mathrm{dad}^{34}$ esta visión plantea como condición la existencia y crecimiento de la vida del sujeto. No habla de un sujeto en abstracto sino de un sujeto real con necesidades y enfrentado al problema de la vida y muerte.

El ser humano establece una relación con su entorno a partir del criterio vida-muerte, todo acto está atravesado por esta reflexión inicial. Juzgamos a los objetos y los fines a partir de la relación de la vida-muerte. Siendo el ser humano un ser vivo enfoca sus acciones siempre en el horizonte de la vida-muerte. De hecho experimentamos (vivimos) la realidad a partir de la dicotomía vida-muerte. Veamos algunos ejemplos:

\section{${ }^{33}$ Loc. cit.}

${ }^{34} \mathrm{El}$ antropocentrismo de la modernidad que terminó por olvidarse del ser humano e hizo una abstracción de él, y en su lugar puso un capitalcentrismo o un mercadocentrismo. 
La ley de la gravedad puede verse de dos formas a partir de una racionalidad instrumental medio fin y a partir de la óptica vida-muerte del sujeto. Como dice Hinkelammert, si me encuentro en el tercer piso de un edificio y deseó ir a la planta baja el que yo tome la decisión de bajar por las escaleras y no arrojarme por la ventana es indicativo de que me comportó a partir del enfoque vida-muerte. Si yo decido arrojarme por la ventana indudablemente llegaré más rápido a la planta baja, pero mi vida está en riesgo, pero como yo decido bajar por las escaleras es significativo de que guío mis actos a partir del problema vida-muerte.

Segundo ejemplo: el sol bajo la óptica vida-muerte no es esa esfera compuesta de hidrógeno, nitrógeno, helio etc., que alcanza grandes temperaturas, que expande sus rayos a la tierra y alrededor de la cual gira nuestro planeta. Por el contrario, ese sol es otro sol, es aquello que yo necesito para vivir pues si no tengo acceso al sol me pongo pálido, me enfermo etc., es decir estamos de nueva cuenta bajo la óptica vida-muerte del sujeto.

Tercer ejemplo: cuando nosotros pedimos agua limpia para calmar nuestra sed, no estamos pidiendo $\mathrm{H}^{2} 0$. Si yo tomo $\mathrm{H}^{2} 0$ me muero - es veneno para mí-. Cuando yo digo agua limpia tengo otra noción completamente diferente de la que tiene el científico cuando trabaja. En realidad estoy pidiendo agua sucia porque el agua potable tiene sales minerales, magnesio etc., entonces está en otra noción completamente diferente de agua limpia. ${ }^{35}$

\section{CONCLUSIONES}

Debemos recobrar la realidad en toda su dimensión, la realidad más real, según Hinkelammert, es la realidad vida-muerte. Sin embargo no siempre el ser humano y las ciencias en particular han sido conscientes de este principio de la vida-muerte, pues en muchas ocasiones se han olvidado

${ }^{35}$ Cfr. Diálogo con Franz Hinkelammert en la Facultad de Filosofía y Letras de la UNAM a invitación de Enrique Dussel. Realizado el 23 de noviembre, 1995. 
que están enfrentados al problema de la vida-muerte y se toman decisiones que como producto de su aplicación repercuten negativamente en la vida del ser humano. Hinkelammert recupera una noción de ética de la vida a partir de la cual es posible realizar la crítica a nociones tradicionalistas de la ética, a posturas reduccionistas de la ética, así como a la llamada ética del discurso de Haberlas y Apel. Estamos ante una ética verdaderamente humanista porque pone en el centro al ser humano concreto, real y no a un falso humanismo como la modernidad capitalista.

Hinkelammert argumenta que existe un criterio que se debe respetar por encima de todos los demás. Este criterio debe someter a los otros para juzgar su factibilidad, que sea posible la vida del ser humano. Con el principio de factibilidad Hinkelammert está en condiciones para evaluar los alcances de la acción humana. Es oportuno señalar que para Hinkelammert estos límites no están predeterminados, sino que se descubren históricamente, cuando el sujeto es consciente de los principios de imposibilidad.

Recibido: 24 de marzo, 2008. Aceptado: 26 de septiembre, 2008. 
BIBLIOGRAFÍA

GutiéRrez, GERMÁn, Ética y economía en Adam Smiht y Friederich Hayek, México, Universidad Iberoamericana, 1996 (Tesis de Maestría publicada por el Departamento Ecuménico de Investigaciones, San José, 1998).

, "Neoliberalismo y ética", en Neoliberalismo y sujeto rebelde: entre la lucha y la desesperanza, vol. I (Antología preparada por José Manuel Arellano, sin editar, 2001) y en Revista Logos, núm. 79, ANUIES.

Hinkelammert, Franz J., Crítica a la razón utópica, San José, Costa Rica, Departamento Ecuménico de Investigaciones (DEI), 1984, p. 240.

,El mapa del emperador, San José, Costa Rica, Departamento Ecuménico de Investigaciones (DEI), 1996.

OtRos

Diálogo en la Facultad de Filosofía y Letras de la UNAM con Franz Hinkelammert, a invitación de Enrique Dussel. Realizado el 23 de noviembre, 1995. 